\title{
Viabilidade econômica do sistema cage-free para poedeiras comerciais
}

\author{
Economic viability of cage-free system for commercial laying hens \\ Viabilidad económica del sistema sin jaulas para gallinas ponedoras comerciales
}

Recebido: 23/11/2021 | Revisado: 02/12/2021 | Aceito: 24/12/2021 | Publicado: 04/01/2022

\author{
José Valmir da Silva Taborda \\ ORCID: https://orcid.org/0000-0002-9850-4236 \\ Instituto Federal de Rondônia, Brasil \\ E-mail: jose.taborda@ifro.edu.br \\ Vanessa Karla Silva \\ ORCID: https://orcid.org/0000-0002-8095-2647 \\ NutriFeed, Brasil \\ E-mail: vanksilva@yahoo.com \\ Sarah Sgavioli \\ ORCID: https://orcid.org/0000-0003-1156-2386 \\ Universidade Brasil, Brasil \\ E-mail: sarahsgavioli@yahoo.com.br
}

\begin{abstract}
Resumo
Com a crescente preocupação do mercado consumidor de alimentos com o bem-estar animal, o setor da avicultura, principalmente na produção de ovos, está sendo forçado a migrar para sistemas alternativos de produção. Com o intuito de auxiliar os produtores na tomada de decisão de investimentos, objetivou-se realizar um estudo de caso e avaliar a viabilidade econômica da implantação de um projeto para a criação de poedeiras no sistema cage-free, desde a construção do galpão até a venda dos ovos. Para isso foi feito o levantamento dos custos para a construção civil da instalação (15m x 150m), aquisição de equipamentos e custos relacionados com a produção os ovos, desde a compra das aves (15.750 aves da linhagem Dekalb brown), ração, vacinas, entre outros. Após a análise dos dados, estes foram submetidos à aplicação dos indicadores financeiros: valor presente líquido, taxa interna de retorno, paybacks simples e descontado e os pontos de equilíbrio: financeiro, contábil e econômico. Para as análises as condições propostas foram: custo de oportunidade $10 \%$, lucro desejado de $15 \%$ e tempo para recuperação do investimento num período projetado de sete anos. Obteve-se um payback simples de 4,25 e o composto de 5,8 anos, valor presente líquido de R\$ $141.504,37$, o que gerou uma taxa interna de retorno de $14,33 \%$ e os percentuais sobre as vendas foram de $49,38 \%$; $35,92 \%$ e $90,46 \%$ para os pontos de equilíbrio contábil, financeiro e econômico respectivamente. Conclui-se que, dentro do que foi proposto, a criação de poedeiras no sistema cage-free é viável financeiramente.
\end{abstract}

Palavras-chave: Avicultura de postura; Bem-estar animal; Indicadores financeiros; Investimento.

\begin{abstract}
With the growing concern of the food consumer market with animal welfare, the poultry sector, mainly in the production of eggs, is being forced to migrate to alternative production systems. In order to assist producers in making investment decisions, the objective was to carry out a case study and assess the economic feasibility of implementing a project for the creation of layers in the cage-free system, from the construction of the shed to the sale of eggs. For this, the costs for the construction of the installation $(15 \mathrm{~m} \mathrm{x} 150 \mathrm{~m})$, acquisition of equipment and costs related to the production of eggs, from the purchase of the birds (15,750 birds of the Dekalb brown lineage), feed, vaccines, were carried out. between others. After analyzing the data, they were submitted to the application of financial indicators: net present value, internal rate of return, simple and discounted paybacks and the balance points: financial, accounting and economic. For the analyses, the proposed conditions were: $10 \%$ opportunity cost, $15 \%$ desired profit and time for investment recovery in a projected period of seven years. A simple payback of 4.25 and a composite of 5.8 years was obtained, net present value of $\mathrm{R} \$ 141,504.37$, which generated an internal rate of return of $14.33 \%$ and the percentages on sales were $49.38 \% ; 35.92 \%$ and $90.46 \%$ for the accounting, financial and economic balance points respectively. It is concluded that, within what was proposed, the creation of layers in the cage-free system is financially viable.
\end{abstract}

Keywords: Animal welfare; Egg production; Financial indicators; Investment.

\section{Resumen}

Con la creciente preocupación del mercado consumidor de alimentos por el bienestar animal, el sector avícola, principalmente en la producción de huevos, se ve obligado a migrar hacia sistemas de producción alternativos. Con el fin de ayudar a los productores en la toma de decisiones de inversión, el objetivo fue realizar un estudio de caso y evaluar la viabilidad económica de implementar un proyecto para la creación de ponedoras en el sistema libre de 
jaulas, desde la construcción del galpón hasta la venta de huevos. Para isso foi feito o levantamento dos custos para a construção civil da instalação (15m x 150m), aquisição de equipamentos e custos relacionados com a produção os ovos, desde a compra das aves (15.750 aves da linhagem Dekalb brown), ração, vacinas, entre otros. Después de analizar los datos, se sometieron a la aplicación de indicadores financieros: valor actual neto, tasa interna de retorno, amortizaciones simples y descontadas y los puntos de equilibrio: financiero, contable y económico. Para los análisis, las condiciones propuestas fueron: $10 \%$ de costo de oportunidad, $15 \%$ de ganancia deseada y tiempo de recuperación de la inversión en un período proyectado de siete años. Se obtuvo una amortización simple de 4,25 y un compuesto de 5,8 años, valor presente neto de R \$141.504,37, que generó una tasa interna de retorno del 14,33\% y los porcentajes sobre las ventas fueron del 49,38\%; 35,92\% y 90,46\% para los puntos de equilibrio contable, financiero y económico respectivamente. Se concluye que, dentro de lo propuesto, la creación de ponedoras en el sistema libre de jaulas es económicamente viable.

Palabras clave: Avicultura ponedora; Bienestar de los animales; Indicadores financieros; Inversión.

\section{Introdução}

Sistemas de gaiola convencionais foram desenvolvidos na década de 30 do século XX e usados na produção tradicional de ovos desde a década de 50. Estes sistemas foram usados durante um longo tempo e seu único propósito era maximizar o lucro e a produtividade com mais aves sendo alocadas em uma pequena área para maior produtividade de ovos (Sosnowka-Czajka et al., 2010; Jones et al., 2014; Jones et al., 2018). O bem-estar animal ganhou importância e o sistema convencional de gaiolas foi questionado devido à restrição de movimentos e expressão dos comportamentos, devido à falta de espaço e o comprometimento da ambiência (Mench et al., 2011).

Dos consumidores brasileiros de produtos de origem animal, $88 \%$ acreditam que o tratamento dos animais de produção precisava melhorar (World Society for the Protection of Animal, 2007) 85\% estão dispostos a pagar mais por um produto produzido de acordo com as normas de bem-estar animal (Instituto Brasileiro de Opinião Pública e Estatística, 2008).

A partir desta demanda surgiu o desenvolvimento de sistemas de criação alternativos, que visam o bem-estar das aves, permitindo assim que as aves expressem seus comportamentos naturais.

Dentre os tipos de sistemas alternativos para a produção de ovos, destaca-se o cage free. Este sistema possui uma série de poleiros, ninhos, linhas de bebedouros e comedouros no seu interior. Seu uso requer mudança para o produtor, pois necessita de alteração no manejo das aves e, portanto, na maior mão de obra. A produção sem gaiolas vem com novos desafios em comparação ao sistema convencional, pois permite que as aves utilizem os espaços verticais e horizontais no interior do galpão, o que requer maiores edificações para alojar a mesmo número de aves presentes na criação convencional. Portanto, estudos que avaliem a viabilidade econômica de tal sistema são imprescindíveis para o desenvolvimento da avicultura de postura.

Não existe na literatura estudos relacionados aos custos de produção de ovos de poedeiras comerciais em sistema cage-free. Portanto, este levantamento poderá contribuir para a tomada de decisões dos produtores que optarem por criar aves neste tipo de sistema.

No Brasil, do ano de 2011 até o de 2019 as exportações mantiveram-se estáveis, representando 1\% do total produzido (Associação Brasileira de Proteína Animal, 2020). Além da exigência interna dos consumidores, quanto ao bem-estar das aves, existem as exigências quanto a exportação de ovos. Motivada pela exigência ética dos seus consumidores nos anos 90, a União Europeia aprovou a Diretiva 1999/74/CE, que proibiu a criação de poedeiras em gaiolas a partir de 2012. Em 06 de novembro de 2018, na Califórnia, ficou estabelecido por meio da Proposição 12 que a partir do ano de 2022 será proibida a criação de poedeiras em instalações, que não permitam aos animais deitar-se, levantar-se, virar-se livremente e estender seus membros completamente (Legislative Analyst's Office, 2018).

Levando-se em consideração as exigências quanto a exportação de ovos e o crescimento interno quanto ao bem-estar das aves, existe a demanda de estudos sobre a viabilidade financeira de sistemas alternativos de produção de ovos. Portanto, o estudo teve como objetivo avaliar a viabilidade econômica e financeira da implantação de um sistema de criação cage-free para 
poedeiras comerciais.

\section{Metodologia}

A pesquisa foi classificada como um estudo de caso, onde os dados e resultados obtidos não podem ser extrapolados para situações diferentes das analisadas. Realizou-se o levantamento de preços por meio de pesquisa de mercado com orçamentos de empresas especializadas no ramo da avicultura.

Foi considerado o modelo de criação de poedeiras comerciais no sistema cage-free com galinhas Dekalb Brown. O orçamento para a construção civil da instalação e equipamentos necessários foi fornecido por uma empresa do ramo, sendo considerados os preços obtidos na Internet e o preço da ração cotado para Vilhena -RO. Para este estudo de caso foi desconsiderado o preço da propriedade rural e o orçamento foi realizado para um galpão.

Para a construção do galpão de estrutura metálica (Figura 1), foram considerados os seguintes padrões: rede elétrica trifásico 220V; comprimento do galpão - 150 metros; largura: 15 metros; perfazendo $2.250 \mathrm{~m}^{2}$; altura pé direito: 2,50 metros; sem forração. Diferente das estruturas de madeira e de concreto, a construção do galpão de estrutura metálica não gera entulho e nem desperdício de material. Tudo é feito na indústria, e a estrutura chega pronta ao canteiro para ser instalada por uma equipe especializada em estrutura metálica para galpão.

Figura 1 - Planta baixa do galpão.

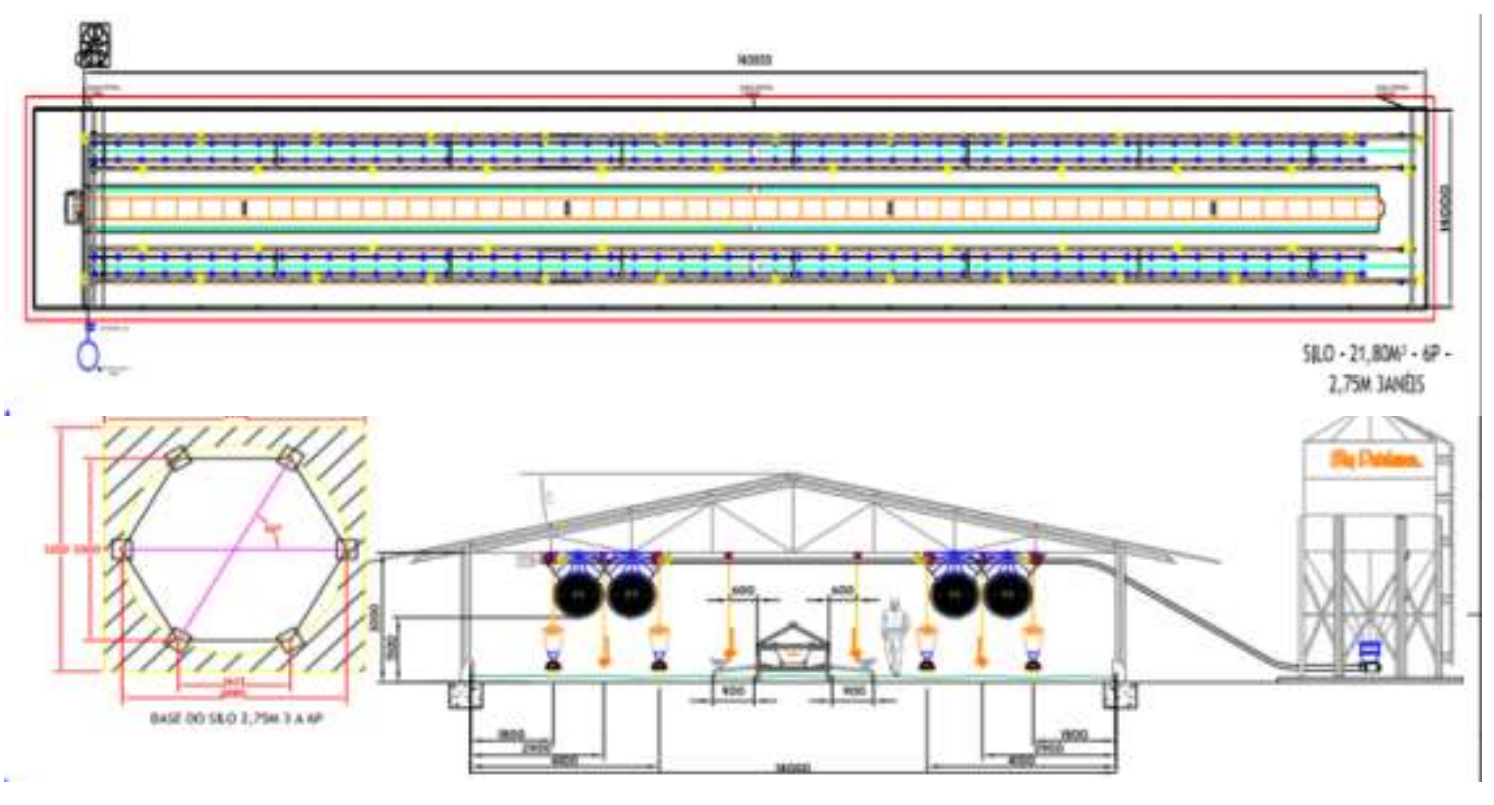

Fonte: Autores.

Para viabilizar a criação das aves em sistema cage-free se faz necessário a aquisição dos equipamentos:

- Sistema de produção de ovos postura: composto por um ninho automático com 62 módulos fechados, sendo três módulos de passagem, com 149,54 metros lineares de comprimento útil, com largura de $1.530 \mathrm{~mm}$ e altura de 1.435 $\mathrm{mm}$. Área interna de $2,4 \mathrm{~m}^{2}$ com quatro repartições com área interna livre para as aves de $0,6 \mathrm{~m}^{2}$ por repartição, com capacidade máxima de 340 aves por módulo com largura de slat (piso plástico) de 1,20 m.

- Mesa de coleta de ovos: capacidade de 258,06 aves/módulo; pés em aço inox com regulagem de altura; fechamento em compensado naval marítimo com suporte em inox; conjunto de expulsão independente com seis unidades; três módulos de passagem; esteira transportadora de ovos central com $500 \mathrm{~mm}$ de largura; e antipoleiro cumeeira do ninho. 
- Conjunto comedouro automático: composto por quatro linhas de 153 metros com 204 pratos/linha, total de 816 pratos.

- Silo de armazenagem de ração com capacidade para $24,5 \mathrm{~m}^{3}$, composto por tubos de seis metros, com diâmetro de 45 $\mathrm{mm}$.

- Sistema de climatização: tecido de cortinado laminado azul/prata $120 \mathrm{~g} / \mathrm{m}^{2}$; conjunto de travamento/suspensão a cada cinco metros com gancho passante $30 \mathrm{~cm} ; 26$ ventiladores; 2 exaustores; cabeamento elétrico/bocal para lâmpadas; painel de controle; conjunto de vedação com envelopamento e bando em "Y"; sistemas nebulizadores média pressão netafim 120 bicos.

- Sistema de bebedouro automático: composto por oito linhas de $76,5 \mathrm{~m}$ com barras de $3 \mathrm{~m}$ com 12 bicos, perfazendo um total de 2.448 bicos com as características, com bebedouro nipple, com 4.024 taça com reguladores de pressão, sendo um regulador total por linha; 5,08 aves por bico; sistema de suspensão a cada $3 \mathrm{~m}$, com um guincho por linha; sistema de choque; sistema de entrada d'agua com painel, hidrômetro 3/4", filtro e caixa d'água 1.000 L.

O manejo das poedeiras será de acordo com as recomendações do manual de manejo da linhagem Dekalb Brown (2008), seguindo os aspectos referentes à transferência para o galpão de postura, oferecendo água de qualidade, sanidade e alimentação balanceada de acordo com as exigências nutricionais da linhagem. Após o descarte do lote o galpão deverá ser preparado para a recepção de novas aves levando-se em consideração a limpeza e desinfecção e o vazio sanitário que, segundo Mazzuco et al. (2006) e Santana et al (2020) é, em média, de 20 dias. O vazio sanitário (20 dias) equivale a aproximadamente $4 \%$ do período de 504 dias de produção, que aplicado proporcionalmente ao ano, para cômputo de despesas fixas nesse período será de aproximadamente 13,93 dias/ano.

Ainda de acordo com o manual da linhagem o programa de vacinação para aves a partir de 17 semanas deve incluir proteção contra doença de newcastle, bronquite infecciosa, encefalomielite aviária, bouba aviária, gumboro entre outras doenças de acordo o desafio da granja ou região. As vacinas orçadas foram Inter Multi 6 vacina sêxtupla contra a síndrome da queda de postura, doença de newcastle, bronquite infecciosa e coriza infecciosa das aves; sorotipos A (221), B (222) e C (modesto) com 1.000 doses e vacina encefalomielite aviária (Provac-AE) também com 1.000 doses.

Segundo as exigências da Humane Farm Animal Care (2018a) para a produção de poedeiras em sistema cage-free, a densidade deve ser de $0,14 \mathrm{~m}^{2} /$ ave o que equivale a 7,14 aves $/ \mathrm{m}^{2}$, sendo assim, os cálculos foram feitos levando em consideração a quantidade de 7 aves $/ \mathrm{m}^{2}$. Portanto para este trabalho foi considerado o alojamento de 15.750 aves.

- Quanto à certificação foram utilizados os valores disponibilizados pela Humane Farm Animal Care (2018b). Este órgão é responsável por certificar a produção de ovos em sistema cage-free. As tarifas de certificação se dividem em:

- Tarifa de solicitação: $\mathrm{R} \$ 375,00$, valor cobrado de novos clientes ou renovações confirmadas até 60 dias antes de cumpridos 12 meses da última inspeção anual; $R$ \$ 750,00 para renovações confirmadas entre 60 e 30 dias antes de cumpridos 12 meses da última inspeção anual e R \$1.500,00 para renovações confirmadas com menos de 30 dias antes de cumpridos 12 meses da última inspeção anual.

- Tarifa de inspeção: a tarifa mínima da Humane Farm Animal Care para realizar inspeções em fazendas ou granjas é de $\mathrm{R} \$ 1.800,00 /$ dia/inspetor. Além desse custo o operador é responsável pelas despesas de logística do inspetor.

- Tarifa de certificação: a tarifa de certificação da Humane Farm Animal Care é devida sobre todos os produtos licenciados para venda como Certified Humane ${ }^{\circledR}$ por um produtor, fazenda ou granja certificados. São tarifas mensais que devem ser calculadas sobre todos os produtos licenciados, independentemente do uso ou não do selo de certificação no produto final, sendo de $\mathrm{R} \$ 0,1282 /$ caixa com 30 dúzias de ovos.

A tarifa de certificação para venda como Certified Humane® foi designada como despesa variável; a tarifa de solicitação anual, as tarifas de inspeção e despesas com o inspetor foram designadas como despesas fixas. 
No estudo foi considerada a TMA em $10 \%$ ao ano, arredondada de $9,94 \%$. Esta foi a taxa do sistema especial de liquidação e custódia (SELIC) acumulada no ano de 2017, o que equivale a aproximadamente $0,8 \%$ ao mês. A taxa SELIC foi adotada por ser a maior entre as taxas referências para análise de investimentos em respeito ao princípio da prudência.

Para o estudo da viabilidade financeira e econômica do projeto foram utilizadas ferramentas de análise tais como playbacks simples e descontado (Eq. 1), valor presente líquido considerando a taxa mínima de atratividade (Eq. 2), taxa interna de retorno do investimento considerando o valor presente líquido igual a zero (Eq. 3) e os pontos de equilíbrio contábil (Eq. 4), financeiro (Eq. 5) e econômico (Eq. 6).

O payback simples pode ser calculado ao se usar o fluxo de caixa simples ou o payback descontado se usar o fluxo de caixa descontado:

$$
P B=U P F C A n-\frac{U F C A n}{F C P S}
$$

(Eq. 01)

Onde:

PB: payback;

UPFCAn: último período de fluxo de caixa acumulado negativo;

UFCAn: último fluxo de caixa acumulado negativo;

FCPS: fluxo de caixa do período seguinte.

$$
V P L=\frac{F C_{1}}{(1+T M A)^{1}}+\frac{F C_{2}}{(1+T M A)^{2}}+\frac{F C_{3}}{(1+T M A)^{3}}+\cdots+\frac{F C_{n}}{(1+T M A)^{n}}+F C_{0}
$$

(Eq. 02)

Onde:

$V P L$ : valor presente líquido;

$F C_{n}$; fluxo de caixa por período;

$F C_{0}$ : fluxo de caixa inicial;

$F C_{n}$ : fluxo de caixa por período;

TMA: taxa mínima de atratividade;

$n$ : períodos.

$$
V P L=C F_{0}+\frac{C F_{1}}{(1+T I R)^{1}}+\frac{C F_{2}}{(1+T I R)^{2}}+\frac{C F_{3}}{(1+T I R)^{3}}+\cdots+\frac{C F_{n}}{(1+T I R)^{n}}=0
$$

Onde:

$V P L$ : valor presente líquido; 
$C F_{0}$ : fluxo de caixa inicial;

$C F_{n}$ : fluxo de caixa por período (receita do período menos os gastos do período);

TIR: taxa interna de retorno;

$n$ : períodos.

$$
\text { PEC }=\frac{\text { Gastosfixos }}{\text { MargemdeContribuiģ̊ิ }}
$$

(Eq. 04)

$$
P E F=\frac{(\text { Gastosfixos-Gastosnâodesembolsáveis) }}{\text { MargemdeContribuị̧̧âิo }}
$$

(Eq. 05)

$$
P E E=\frac{(\text { Gastosfixos }+ \text { LweroDesejado })}{\text { MargemdeContribuiģẫo }}
$$

(Eq. 06)

Onde:

PEC: ponto e equilíbrio contábil;

PEF: ponto de equilíbrio financeiro;

PEE: ponto de equilíbrio econômico;

Gastosfixos: são custos e despesas que independem de produção, ex: conservação, aluguéis, etc;

Gastosnãodesembolsáveis: são custos e despesas que não necessitam de saídas de caixa, ex: depreciação de instalações e equipamentos;

Lucrodesejado: lucro esperado pelo administrador.

Margemdecontribuição: receita de venda menos os gastos variáveis e estes são os gastos que aumentam ou diminuem diretamente proporcional à produção.

\section{Resultados e Discussão}

\subsection{Gastos com construção, equipamentos e manejos}

O valor da construção civil e equipamentos, composto por sistema de produção de ovos, climatização, conjunto de comedouro e bebedouro automático, ninhos e silo foi de R $\$ 963.563,39$ (Tabela 1). 
Tabela 1 - Gastos em reais para a construção civil da instalação e aquisição dos equipamentos.

\begin{tabular}{lc}
\hline Edificações & \\
\hline Construção civil galpão & $500.000,00$ \\
Outras edificações* & $100.000,00$ \\
\hline Equipamentos & $211.081,90$ \\
\hline Sistema de produção de ovos & $39.652,00$ \\
Conjunto comedouro automático & $69.845,88$ \\
Sistema de climatização avícola & $24.483,61$ \\
Sistema de bebedouro automático & $18.500,00$ \\
Montagem do sistema de bebedouro & $\mathbf{9 6 3 . 5 6 3 , 3 9}$ \\
\hline Total
\end{tabular}

* atendimento ao princípio contábil da prudência. Fonte: Elaborado pelos autores.

Devido ao orçamento ser uma projeção de gastos com edificações, máquinas e equipamentos foram feitas provisões de gastos de $\mathrm{R} \$ 100.000,00$ alocados para outras edificações, pois assim tem-se um valor provisionado para eventuais gastos que não estejam previstos devido às possíveis falhas de orçamento. Esta provisão foi orçada em atendimento ao princípio contábil da prudência que determina a adoção do menor valor para os componentes do ativo e do maior para os do passivo, sempre que se apresentem alternativas igualmente válidas para a quantificação das mutações patrimoniais que alterem o patrimônio líquido (Bugarim \& Jinzenji, 2008).

Os valores da remuneração dos funcionários (dois) e o pró-labore do sócio administrativo (um) foram feitos sobre o salário base de $\mathrm{R} \$ 1.500,00$ e de $\mathrm{R} \$ 3.000 .00$, respectivamente, de acordo com as leis trabalhistas (Tabela 2).

Tabela 2 - Cálculo anual da mão de obra de um funcionário pró-labore e dois funcionários.

\begin{tabular}{lc}
\hline Itens & Valores mensais em R\$ \\
\hline Pró-labore & $2.760,00$ \\
\hline Salário funcionários e pró-labore & $2.331,05$ \\
INSS & $2.244,00$ \\
FGTS & 240,00 \\
Imposto de renda retido na fonte & 218,95 \\
Férias e $1 / 3$ férias & 306,67 \\
$13^{\circ}$ salário & 230,00 \\
\hline Total & $\mathbf{8 . 3 3 0 , 6 7}$ \\
\hline
\end{tabular}

Fonte: Elaborado pelos autores.

Dividiu-se os gastos anuais em fixos e variáveis (Tabela 3), onde os custos fixos não dependem do volume de produção, enquanto que os custos variáveis são alterados em função do volume de produção da empresa (Lima, 2014). 
Tabela 3 - Gasto anual variáveis e fixos para a produção de ovos de poedeiras em sistema cage free.

\begin{tabular}{|c|c|c|c|}
\hline & Unitário (R\$) & Quantidade & Total $(\mathbf{R} \$)$ \\
\hline & \multicolumn{3}{|c|}{ Variáveis } \\
\hline Franga recriada & 14,00 & 15.750 & $153.592,56$ \\
\hline Ração postura (kg) & 0,86 & $632.394,56$ & $543.859,32$ \\
\hline Vacina Inter Multi 6 & 550,00 & 15,75 & $8.662,50$ \\
\hline Vacina encefalomielite aviária & 70,00 & 15,75 & $1.102,50$ \\
\hline Tarifa de certificação/ovo & 0,1282 & 11.974 & $1.535,06$ \\
\hline Outras despesas variáveis* & & & $70.875,10$ \\
\hline \multirow[t]{2}{*}{ Total de gastos variáveis } & & & 779.627,13 \\
\hline & \multicolumn{3}{|c|}{ Fixos } \\
\hline Mão de obra & $8.330,67$ & 12 & $99.968,04$ \\
\hline Energia elétrica & $1.500,00$ & 12 & $18.000,00$ \\
\hline Água & 500,00 & 12 & $6.000,00$ \\
\hline Telefone e internet & 400,00 & 12 & $4.800,00$ \\
\hline Depreciação & $5.029,79$ & 12 & $60.357,48$ \\
\hline Certificação: solicitação anual & 31,25 & 12 & 375,00 \\
\hline Certificação: inspeção & 375,00 & 12 & $4.500,00$ \\
\hline Vazio sanitário & 687,53 & 12 & $8.250,40$ \\
\hline Outros gastos fixos* & $1.600,00$ & 12 & $19.200,00$ \\
\hline Total gastos fixos & & & $221.449,74$ \\
\hline Total de gastos & & & 1.001.076,87 \\
\hline
\end{tabular}

* atendimento ao princípio contábil da prudência. Fonte: Elaborado pelos autores.

Sobre os custos variáveis considerou-se a aquisição de poedeiras recriadas, com 17 semanas, ao preço de R\$ 14,00/ave. Este valor foi obtido por meio de visita técnica à uma granja cage-free no estado de São Paulo. O custo com a compra das aves anual foi calculado levando-se em consideração o ciclo de postura (524 dias), o número de aves para tal ciclo (15.750) e o valor unitário das aves com 17 semanas de idade ( $\mathrm{R} \$ 14,00)$ (Tabela 3). Portanto, fez-se o seguinte cálculo: 365dias/524dias*15.750*14 = R \$ 153.592,56/ano.

Com relação ao cálculo da ração, de acordo com o manual de manejo da linhagem (Dekalb Brown, 2008) a média do consumo de ração/ave/dia é de $0,112 \mathrm{~kg}$, considerando um desperdício de cinco gramas/ave/dia utilizou-se, para os cálculos, um consumo de $0,117 \mathrm{~kg} / \mathrm{ave} / \mathrm{dia}$ o que resulta em um consumo de ração de 42,705 kg/ave/ano, porém, considerando uma mortalidade de $6 \%$ o consumo anual de ração será de 632.394,56kg para o lote. Assim, obteve-se o gasto anual com ração de $\mathrm{R} \$ 543.859,32$. O valor da ração para o ano de 2018, obtido por meio da visita técnica é de $\mathrm{R} \$ 0,86 / \mathrm{kg}$ (Tabela 3 ).

Considerando que todas as aves serão vacinadas nos primeiros dias que forem alojadas no galpão serão usadas 15,75 unidades de 1.000 doses de cada tipo de vacina ao custo de $\mathrm{R} \$ 550,00$ e $\mathrm{R} \$ 70,00$, para Multi 6 e Provac-AE, respectivamente (Tabela 3).

O item outras despesas variáveis representa $10 \%$ do valor da compra das frangas somado às despesas com o consumo de ração e gastos com vacinas provisão esta estipulada em respeito ao princípio contábil da prudência (Bugarim \& Jinzenji, 2008). Gastos como bandeira tarifária de energia elétrica deverão ser incluídos no item denominado Outros gastos fixos*, uma vez que este absorve este gasto que porventura venha se tornar realidade dentro dos períodos analisados, haja vista, esse valor ser um "adicional" aos gastos justamente para atender o princípio da prudência que determina a adoção do menor valor para os componentes do ativo e do maior para os do passivo, sempre que se apresentem alternativas igualmente válidas para a quantificação das mutações patrimoniais que alterem o patrimônio líquido (BUGARIM \& JINZENJI, 2008).

Para chegar aos gastos com telefone e internet foram feitas consultas às empresas de telefonia e fornecedores de sinal de internet via fibra ótica. Em relação à energia elétrica e água foi realizado levantamento dos custos com granjas de poedeiras comerciais criadas em sistema cage-free (Tabela 3).

Quanto à certificação adotou-se, para esse trabalho, o valor de R \$ 375,00 para a solicitação anual e um valor de R\$ 4.500,00 para os custos com a inspeção, compreendendo a despesas de logísticas (transporte R \$ 150/dia, acomodação R \$ 
200,00/dia e alimentação $R$ \$ 100,00/dia, em um total de $R$ \$ 900,00) e mão de obra ( $R$ \$ 3.600,00) para dois dias de inspeção (Tabela 3).

Para o cálculo da depreciação foi respeitado o Artigo 124 da Instrução Normativa (IN) da Receita Federal do Brasil (RFB) n 1700/2017 (Receita Federal, 2017). Onde se destaca que a taxa anual de depreciação é fixada em função do prazo durante o qual se possa esperar a utilização econômica do bem pelo contribuinte, na produção dos seus rendimentos, e no anexo III, da IN acima citada, são dados os prazos de vida útil para instalações de dez anos e das edificações de 25 anos, com depreciações de 10 e $4 \%$ ao ano, respectivamente. Observando que não foram considerados valor residual para ambos os itens depreciáveis. Considerou-se como instalações o conjunto de máquinas e equipamentos (Tabela 3).

O valor do vazio sanitário, foi calculado levando-se em consideração o gasto fixo mensal/dia (GFM/dia = 17.766,61/30), a proporção que 365 dias representa em 524 dias de produção e o número de dias do vazio sanitário (20 dias) (Tabela 3). Portanto, fez-se o seguinte cálculo: $(17.766,61 / 30) *((365 / 524) * 20)=\mathrm{R} \$ 8.250,40$.

Fez-se uma provisão mensal para gastos fixos de $\mathrm{R} \$ 1.600,00$ para eventuais aumentos dos gastos no decorrer do ano, provisão esta estipulada em respeito ao princípio contábil da prudência (Bugarim \& Jinzenji, 2008).

\subsection{Resultado do período}

A produção esperada é de 418 ovos/ave alojada em 72 semanas ou 504 dias (Dekalb Brown, 2008). Para efeito de cálculo para produção incluiu-se o vazio sanitário (20 dias) elevando o ciclo de postura para 524 dias.

Sarcinelli et al. (2007) estimam que na fase de produção o índice de mortalidade de poedeiras pode variar entre 8 e $10 \%$. Portanto, estimou-se uma redução de $6 \%$ na produção de ovos, haja vista, o decréscimo devido às mortes das aves ao longo do período de produção. Não foi usado o valor da linhagem por ser menor e assim, uma vez a despesa é majorada, dentro de um parâmetro aceitável para a contabilidade de custos gerando a probabilidade de o projeto ter êxito dentro do prazo determinado para o retorno do investimento.

A média anual de postura por ave foi calculada da seguinte forma: $\bar{x}=365$ dias/524dias*418 $=291,16$, mas considerando a redução de $6 \%$ devido à mortalidade tem-se uma produção total de aproximadamente 11.974 caixas com 30 dúzias/ano. Este valor foi utilizado para o cálculo dos gastos com a certificação dos ovos.

O peso médio do ovo da linhagem em questão é de 62,6 g o que o classifica como grande (Dekalb Brown, 2008). Para que não se corra o risco de a receita de vendas ser superestimada apesar do ovo da linhagem Dekalb Brown ser classificado como grande foi adotado o preço de venda do ovo médio de $\mathrm{R} \$ 101,70 /$ caixa de 30 dúzias (Tabela 4).

As aves ao final do seu ciclo produtivo serão descartadas sendo vendidas ao valor de $R$ \$ 1,00/ave. Portanto, para o cálculo da receita anual com a venda das aves de descarte levou-se em consideração o número de dias do ciclo de produção (524 dias) e o número de aves compradas com 17 semanas (15.750). Assim, fez-se o seguinte cálculo: 365/524*15.750*0,94 = $\mathrm{R} \$ 10.312,64 /$ ano para a receita com a venda das aves (Tabela 4)

Destas receitas compiladas foram descontados os gastos variáveis e fixos, para se obter a demonstração do resultado do exercício (DRE) projetada (Tabela 5).

Tabela 4 - Demonstração do resultado do exercício projetado anual.

\begin{tabular}{lccc}
\hline & Unitário (R\$) & Quantidade & Total (R\$) \\
\hline Receita com a venda dos ovos & 101,70 & $11.973,96$ & $1.217 .751,22$ \\
Receita com a venda das aves & 1,00 & $10.312,64$ & $10.312,64$ \\
Gastos variáveis e fixos & & & $1.001 .076,87$ \\
Lucro projetado & & & $226.987,00$ \\
\hline
\end{tabular}

Fonte: Elaborado pelos autores. 


\subsection{Análise dos indicadores financeiros}

Para os fluxos de caixa simples e descontado (Eq. 7), na linha do período zero encontra-se o valor do investimento inicial que aparece negativo, pois representa as saídas de caixa, na coluna "fluxo de caixa" a partir do período um aparecem a previsão de resultado dos períodos, sem considerar o valor do dinheiro no tempo, enquanto que, na coluna "fluxo de caixa descontado" tem-se os valores futuros trazidos a valor presente, por exemplo, no final do período um, o fluxo de caixa simples é de $\mathrm{R} \$ 226.987,00$ já o fluxo de caixa descontado, no mesmo período, é de $\mathrm{R} \$ 206.367,00$, ou seja, este valor é o fluxo de caixa simples do período um (futuro) trazido ao período zero (presente) considerando a TMA de 10\% (Tabela 5).

Tabela 5 - Fluxos de caixa simples e descontado.

\begin{tabular}{lcccc}
\hline $\begin{array}{l}\text { Período } \\
\text { (ano) }\end{array}$ & $\begin{array}{c}\text { Fluxo de caixa } \\
\text { simples }(\mathbf{R} \mathbf{)})\end{array}$ & $\begin{array}{c}\text { Fluxo de caixa simples } \\
\text { acumulado }(\mathbf{R} \mathbf{)}\end{array}$ & $\begin{array}{c}\text { Fluxo de caixa } \\
\text { descontado }(\mathbf{R} \$)\end{array}$ & $\begin{array}{c}\text { Fluxo de caixa descontado } \\
\text { acumulado }(\mathbf{R} \mathbf{)})\end{array}$ \\
\hline 0 & $-963.563,39$ & $-963.563,39$ & $-963.563,39$ & $-963.563,39$ \\
1 & $226.987,00$ & $-736.576,39$ & $206.351,81$ & $-757.211,58$ \\
2 & $226.987,00$ & $-509.589,40$ & $187.592,56$ & $-569.619,02$ \\
3 & $226.987,00$ & $-282.602,40$ & $170.538,69$ & $-399.080,33$ \\
4 & $226.987,00$ & $-55.615,41$ & $155.035,17$ & $-244.045,15$ \\
5 & $226.987,00$ & $171.371,59$ & $140.941,07$ & $-103.104,09$ \\
6 & $226.987,00$ & $398.358,59$ & $128.128,24$ & $25.024,15$ \\
7 & $226.987,00$ & $625.345,58$ & $116.480,22$ & $141.504,37$ \\
\hline
\end{tabular}

Fonte: Elaborado pelos autores.

O VPL do final do sétimo período, que foi o prazo máximo proposto para esta pesquisa, será de R $\$ 141.504,37$, no entanto, ao observar a coluna "fluxo de caixa descontado acumulado" vê-se que no final do sexto período já se tem R $\$ 25.024,15$ positivo, portanto pela análise do VPL, considerando a TMA de $10 \%$ e o volume do investimento este sistema de criação é viável (Tabela 6).

Observando o payback simples conclui-se que com 4,25 períodos o retorno do investimento já será alcançado, porém este não considera a remuneração do dinheiro no tempo, portanto o payback que deve ser levado em consideração é o payback descontado, pois traz para o valor presente a previsão de gastos e ganhos no tempo. Assim, segundo o payback descontado, tem-se que com 5,8 períodos já se é possível contemplar o retorno do investimento, ou seja, o investidor poderá ter recuperado o investimento nos equipamentos e edificações em aproximadamente 70 meses (Tabela 6).

No final do sétimo período a taxa interna de retorno (TIR) é de 14,33\%. Esta é a taxa que torna o VPL do fluxo de caixa descontado acumulado do sétimo período, trazido a valor presente, igual a zero, em outras palavras: se $14,33 \%$ fosse a TMA o VPL do sétimo período que é de R \$141.504,37 seria zero trazido a valor presente (Tabela 6).

A TMA do projeto é de 10\%, mas foi obtido uma TIR de 14,33\% portanto, do ponto de vista da TIR o investimento é viável, pois em termos percentuais a riqueza gerada pelo projeto é de 4,33\% (TIR - TMA), considerado o retorno do investimento (Tabela 6). 
Tabela 6 - Valor presente líquido, taxa interna de retorno e paybacks simples e descontado.

\begin{tabular}{lr}
\hline Taxa de desconto/taxa mínima de atratividade/ taxa do sistema especial de liquidação e custódia (\%) & 10 \\
\hline Valor presente líquido (R\$) & $141.504,37$ \\
Taxa interna de retorno no $7^{\circ}$ período (\%) & 14,33 \\
Payback simples & 4,25 \\
Payback descontado & 5,80 \\
\hline
\end{tabular}

Fonte: Elaborado pelos autores.

\subsection{Pontos de equilíbrio contábil, financeiro e econômico}

A partir da previsão das vendas, de 11.974 caixas de ovos/ano se calculou o percentual das vendas que representa o ponto de equilíbrio, assim, a partir desse percentual obteve-se a quantidade de unidades vendidas e a consequente receita necessária para atingir o ponto de equilíbrio, que pode ser contábil, financeiro ou econômico.

Tais percentuais referem-se às vendas necessárias para cobrir os gastos fixos. Onde no ponto de equilíbrio financeiro não se leva em consideração os gastos fixos não desembolsáveis, no contábil são alocados todos os gastos fixos inclusive a depreciação e no econômico soma-se a todos os gastos e o lucro desejado (Martins, 2010).

O primeiro indicador financeiro a se alcançar é o ponto de equilíbrio financeiro, haja vista, ser necessário a venda de $35,92 \%$ da produção para atingi-lo, ou seja, 4.301,44 em unidades ou R\$ 437.446,77 (Tabela 7).

No entanto, é preciso considerar os gastos não desembolsáveis, por exemplo, depreciação, os quais em algum momento a empresa terá que repor com a compra de novos equipamentos ou reformas no galpão. Portanto, o ponto de equilíbrio contábil é atingido ao ser vendido 49,38\% da produção, as vendas equivalem a 5.913,05 caixas de ovos ou ainda, R\$ 601.357,19 (Tabela 7), ou seja, a partir deste momento passa-se a ter lucro sobre as vendas, com o pagamento total dos custos fixos, restando apenas para cada unidade vendida o seu respectivo custo variável.

Por último foi analisado o ponto de equilíbrio econômico e este por sua vez considera o lucro desejado pelo investidor, o qual, para o presente estudo, foi considerado em $15 \%$ o que fez com que este ponto de equilíbrio fosse atingido ao vender-se $90,46 \%$ da produção, isso implica em 1.0831,73 caixas de ovos ou 1.101.587,12 reais. (Tabela 7).

Observando os pontos de equilíbrio verifica-se uma venda da produção de 49,38, 35,92 e 90,46\% para atingir o contábil, financeiro e o econômico, respectivamente (Tabela 7).

Tabela 7 - Pontos de equilíbrio contábil, financeiro e econômico.

\begin{tabular}{lcrr}
\hline & Venda da produção (\%) & Unidades & \multicolumn{1}{c}{ Receita (R\$) } \\
\hline Ponto de equilíbrio contábil & 49,38 & 5913,05 & $601.357,19$ \\
Ponto de equilíbrio financeiro & 35,92 & 4301,44 & $437.456,77$ \\
Ponto de equilíbrio econômico & 90,46 & 10831,73 & $1.101 .587,12$ \\
\hline
\end{tabular}

Fonte: Elaborado pelos autores.

Para uma gestão prudente deve-se observar o ponto de equilíbrio econômico $(90,46 \%)$, pois este inclui todos os gastos desembolsáveis, os gastos não desembolsáveis e o lucro desejado.

\section{Conclusão}

Neste estudo, verificou-se que, dentro das condições propostas: custo de oportunidade (TMA) de 10\% (taxa SELIC acumulada de 2017), lucro desejado de $20 \%$ e tempo para recuperação do investimento em até 7 anos, a criação da poedeira no sistema cage-free é viável, pois além de ter os pontos de equilíbrio considerados bons ainda tem o Payback descontado de 4,48 
períodos, gerando uma taxa interna de retorno de $21,42 \%$ gerando assim, a partir do 4,48 períodos, uma riqueza de $11,42 \%$ para o empreendimento.

Assim, após avaliar a viabilidade econômica e financeira dos investimentos para implantação do sistema de criação cage-free para poedeiras comerciais, conclui-se que o sistema é viável financeiramente, principalmente diante do cenário internacional em relação ao bem-estar animal para a produção e exportação de ovos livres de gaiola.

\section{Referências}

Associação Brasileira de Proteína Animal. (2020) Relatório Anual 2020. http://abpa-br.org/wpcontent/uploads/2020/05/abpa_relatorio_anual_2020_portugues_web.pdf

Bugarim, M. C. C. \& Jinzenji N. (2008). Princípios Fundamentais e Normas Brasileiras de Contabilidade. (3a ed.), CFC, 2008. http://www1.cfc.org.br/uparq/Livro_Principios\%20e\%20NBCs.pdf.

Dekalb Brown. Guia do Produto. (2018). https://www.dekalb-poultry.com/documents/136/DB_cs_c_prod.g_L7150_1_bpt.pdf .

Dumer M. C. R., Silva Junior, A., Mendonça, M. M., Gomes, J. B., \& Souza, A. M. (2018) Contabilidade de custos versus outras informações contábeis na percepção de empreendedores de MPES. https://revistas.unilasalle.edu.br/index.php/desenvolve/article/view/4347

Humane Farm Animal Care (2018a). Galinhas Poedeiras: Referencial de Bnimal. https://d335luupugsy2.cloudfront.net/cms/files/22943/1539199536HFAC_GalinhasPoedeiras18v2.pdf.

Humane Farm Animal Care (2018b). Manual de Drograma. https://d335luupugsy2.cloudfront.net/cms/files/22943/1540833299Manual_de_Diretrizes_HFAC_19v1.pdf .

Instituto Brasileiro De Opinião Pública e Estatística. (2008). II Fórum IBOPE negócios sustentáveis. Sustentabilidade: hoje ou amanhã? http://www.ibope.com.br/forumibope/pesquisa/Forum_oficial_mar08.pdf.

Jones, D. R., Karcher, D. M., \& Abdo Z. (2014). Effect of a commercial housing system on egg quality during extended storage. Poultry Science, 93,.12821288. http://dx.doi.org/ 10.3382/ps.2013-03631

Jones, D. R., Ward, G. E., Regmi, P., \& Karcher, D. M. (2018). Impact of egg handling and conditions during extended storage on egg quality. Poultry science, 97(2), 716-723.

Kruger, S. D., Petri, S. M., Brighenti, J., Oenning, V. \& Zanin, A. (2018). Análise da mensuração contábil dos custos da atividade avícola no sistema de parceria. https://anaiscbc.emnuvens.com.br/anais/article/viewFile/520/520.

Legislative Analyst's Office. (2018). Proposisition 12. https://lao.ca.gov/BallotAnalysis/Proposition?number=12\&year=2018.

Lima, E. B. (2014). Contabilidade de Custos. http://webserver.crcrj.org.br/APOSTILAS/A0084P0449.pdf.

Martins, E. (2010). Contabilidade de Custos. (10a ed.), Atlas.

Mazzuco, H., kunz, A., Paiva, D. P., Jaenisch, F. R. F, Palhares, J. C. P., Abreu, P. G. A., Rosa, P. S. \& Avila, V. S. (2006). Boas Práticas de Produção na Postura Comercial: Circular Técnica 49. https://www.infoteca.cnptia.embrapa.br/infoteca/bitstream/doc/443776/1/publicacaoh0k52t2.pdf.

Mench, J. A., Summer, D. A. \& Rosen-Molina, J. T. (2011) Sustainability of egg production in the United States-The policy and market context. Poultry Science, 90, 229-240. 10.3382/ps.2010-00844

Neves, W. G. das. (2010). Estudo da Viabilidade Econômico Financeira para uma Empresa de Cosméticos.https://lume.ufrgs.br/bitstream/handle/10183/29674/000769598.pdf?sequence=1\&isAllowed=y

Paixão, R. L. (2005). É possível garantir bem-estar aos animais de produção? Revista Conselho Federal de Medicina Veterinária. (36), 66-73.

Receita Federal. (2017) Instrução Normativa RFB No 1700. http://normas.receita.fazenda.gov.br/sijut2consulta/link.action?idAto=81268\&visao=anotado.

Sabbag, O. J., \& Nicodemos, D. (2011). Viabilidade econômica para produção de mel em propriedade familiar. Pesquisas Agropecuárias, 41(1), 94-10. https://www.scielo.br/j/pat/a/4DV9sH4TJPDkgbGGf8rm5wR/?format=pdf\&lang=pt

Saccomani, A. P. O. (2015). Qualidade físico-química de ovos de poedeiras criadas em sistema convencional, cage-free e free-rang. 2015. http://www.iz.sp.gov.br/pdfs/1438973034.pdf

Santana, M. P., Ferreira, D.A. \& Mendes, L. F. C. (2020). Manual de Boas Práticas de Produção de Ovos e Frangos Caipiras. https://www.emater.mg.gov.br/download.do?id=53009

Sarcinelli, M.F.; Venturini, K.S. \& Silva, L.C. (2007). Características dos ovos. http://www.agais.com/telomc/b00707_caracteristicas_ovos.pdf .

Serviço Brasileiro de Apoio às Micro e Pequenas Empresas. (2018). Gestão Financeira: Ponto de equilíbrio. https://www.sebrae.com.br/sites/PortalSebrae/artigos/ponto-de-equilibrio,67ca5415e6433410VgnVCM1000003b74010aRCRD 
Research, Society and Development, v. 11, n. 1, e17611123811, 2022

(CC BY 4.0) | ISSN 2525-3409 | DOI: http://dx.doi.org/10.33448/rsd-v11i1.23811

Sosnowka-Czajka, E., Herbut, E. \& Skomorucha, I. (2010). Effect of different housing systems on productivity and welfare of laying hens. Annals of Animal Science, 10 (4), 349-360.

World Society for the Protection of Animal. (2007). International Farm Animal Survey. Pesquisa conduzida por Ipsos MORI em Novembro de 2007.

Zago, C. A., Weise, A. D. \& Hornburg, R. A. (2009). Importância do Estudo de Viabilidade Econômica de Projetos nas Organizações Comtemporâneas. http://www.convibra.com.br/2009/artigos/142_0.pdf . 